\title{
Possibilidades de enfrentamento da evasão no curso de Licenciatura em Educação do Campo: a pesquisa enquanto instrumento político e social de transformação
}

\author{
Possibilities for coping with evasion in the College Degree in Rural Education: the \\ research as a political and social device for transformation

\begin{abstract}
Posibilidades de enfrentamiento del abandono estudiantil en la Licenciatura en Educación del Campo: la investigación como instrumento político y social de transformación
\end{abstract}

\author{
Roberta Gonçalves Duarte ${ }^{1}$ \\ Débora Monteiro do Amaral ${ }^{2}$
}

\section{Resumo}

Este artigo apresenta as ações de enfrentamento da evasão e da descontinuidade dos estudos propostas como resultado de uma pesquisa que buscou compreender os desafios da permanência estudantil no curso de Licenciatura em Educação do Campo - campus Goiabeiras da Universidade Federal do Espírito Santo (UFES). Também discute as possibilidades e as dificuldades que emergiram na tentativa de aplicação de algumas dessas ações. Considerando a intervenção como uma das características das pesquisas desenvolvidas em mestrados profissionais, a pesquisa participante apresentou-se como uma opção adequada neste estudo. Para a produção dos dados apresentados neste artigo, foram utilizados questionários, entrevistas coletivas e análises compartilhadas, tendo os estudantes do curso como sujeitos ativos em todo o processo. O referencial teórico-metodológico fundamenta-se em Paulo Freire e em teóricos da educação popular e da Educação do Campo. A pesquisa apontou que os desafios da permanência estudantil neste curso articulam-se em uma teia de fatores, cujas motivações podem ser tanto internas quanto externas à Licenciatura em Educação do Campo. Os relatos dos estudantes destacaram o desconhecimento dos discentes e dos próprios docentes em relação aos princípios e concepções desta graduação como uma das principais causas da descontinuidade dos estudos. O estudo mostrou, ademais, que a universidade ainda não está preparada para receber a classe trabalhadora, em especial, a camponesa, havendo a necessidade de reinventar-se para dialogar com as especificidades que o meio rural demanda.

\footnotetext{
1 Mestre em Educação, pelo Programa de Pós-Graduação de Mestrado Profissional em Educação da Universidade Federal do Espírito Santo (UFES). Assistente em administração na UFES. Membro do Grupo de Estudos e Pesquisas Paulo Freire (GEPPF - UFES). E-mail: betagd87@ gmail.com ORCID: https://orcid.org/0000-0003-3873-2605

${ }^{2}$ Doutora em Educação, pelo Programa de Pós-Graduação em Educação da Universidade Federal de São Carlos (UFSCar). Docente do Departamento de Educação, Política e Sociedade da Universidade Federal do Espírito Santo (UFES), com atuação na Licenciatura em Educação do Campo e no Programa de Pós-Graduação de Mestrado Profissional em Educação. Coordenadora do Grupo de Estudos e Pesquisas em Educação do Campo do Espírito Santo (GEPECES) e Membro do Grupo de Estudos e Pesquisas Paulo Freire (GEPPF).

E-mail: deboramdoamaral@gmail.com - ORCID: https://orcid.org/0000-0002-8397-864X
}

Revista Devir Educação, Lavras, vol.5, n2., p.104-125 jul./dez., 2021. 


\title{
OO DEVIR EDUCAÇÃO
}

ISSN: 2526-849X

Palavras-chave: Ensino Superior; Evasão Escolar; Licenciatura em Educação do Campo; Mestrado Profissional; Permanência estudantil.

\begin{abstract}
This article presents the actions to deal with the evasion and discontinuity of the studies proposed as a result of a research that sought to understand the challenges of student's stay in the Rural Education College Degree - Federal University of Espírito Santo State (UFES), in Goiabeiras campus. It debates the possibilities and difficulties that emerged in the attempt to apply some of these actions, as well. Considering the intervention as one of the features of the research developed in a professional Master's degrees, the research presented itself as an adequate option in this study. For the production of the data showed in this article, questionnaires, group interviews and shared analyzes were used with the students of the course as active subjects throughout the process. The theoretical-methodological framework is based on Paulo Freire and on theoreticians of popular education and also Rural Education. The work pointed out that the challenges of a student's stay in this course are articulated in a web of factors, whose motivations can be both internal and external to the Degree in Rural Education. The students' reports emphasize the lack of knowledge of the students and teachers concerning the principles and concepts of this graduation as one of the main causes of the discontinuity of their studies. The work also showed that the university is not yet prepared to receive the working class, especially the peasants, with the need to reinvent itself to dialogue with the specificities that the rural setting requires.
\end{abstract}

Keywords: Higher Education; School evasion; Degree in Rural Education; Professional Master's; Student's stay.

\section{Resumen}

Este artículo presenta las acciones de enfrentamiento del abandono estudiantil y de la discontinuidad de los estudios propuestos como resultado de una investigación que ha buscado comprender los desafíos de la permanencia estudiantil en el curso de Licenciatura en Educación del Campo - campus Goiabeiras de la Universidad Federal de Espírito Santo (UFES). También se discuten las posibilidades y las dificultades que han emergido con el intento de aplicación de algunas de esas acciones. Considerando la intervención como una de las características de las investigaciones desarrolladas en maestrías profesionales, la investigación participante se presentó como una opción adecuada en este estudio. Para la producción de los datos de este trabajo se utilizaron cuestionarios, entrevistas colectivas y análisis compartidas, teniendo a los estudiantes como sujetos activos en todo el proceso. El marco teórico-metodológico se basa en Paulo Freire y en teóricos de la educación popular y de la Educación del Campo. La investigación señaló que los desafíos de la permanencia estudiantil en ese curso se articulan en una red de factores, cuyas motivaciones pueden ser tanto internas como externas a la Licenciatura en Educación del Campo. Los relatos de los estudiantes destacaron el desconocimiento de los discentes y de los propios docentes con relación a los principios y concepciones de esa licenciatura como una de las principales causas de la discontinuidad de los estudios. Este trabajo ha demostrado, además, que la Universidad todavía no está preparada para recibir a la clase trabajadora, en particular a la campesina, teniendo que reinventarse para dialogar con las especificidades que el medio rural demanda.

Revista Devir Educação, Lavras, vol.5, n2., p.104-125 jul./dez., 2021. 


\section{OO DEVIR EDUCAÇÃO}

ISSN: 2526-849X

Palabras clave: Enseñanza Superior; Abandono Estudiantil; Licenciatura en Educación del Campo; Maestría Professional; Permanencia estudiantil.

\section{Introdução}

No Brasil, a discussão sobre a concepção de Educação do Campo tem seu marco em 1998, com a I Conferência Nacional por uma Educação Básica do Campo. Nos períodos anteriores, a educação ofertada para os povos do campo era concebida a partir de intencionalidades que a atrelavam ao mercado, o que se denominava como educação rural.

Frente à ausência de uma educação baseada na diversidade do meio rural, os movimentos sociais do campo se destacaram ao criar alternativas educacionais que atendessem às particularidades campesinas, sendo fundamentais para as discussões sobre a Educação do Campo e a constituição da identidade camponesa.

Segundo Caldart, a identidade do Movimento por uma Educação do Campo consiste na luta dos camponeses por políticas públicas que garantam o seu direito a uma educação que seja no e do campo. "No: o povo tem direito a ser educado no lugar onde vive; Do: o povo tem direito a uma educação pensada desde o seu lugar e com a sua participação, vinculada à sua cultura e às suas necessidades humanas e sociais" (CALDART, 2011, p. 149, grifos da autora).

Essa luta é compartilhada por diversos sujeitos sociais, pensada com e a partir de um recorte específico de classe, surgido em um contexto de "[...] violenta desumanização das condições de vida no campo. Uma realidade de injustiça, desigualdade, opressão, que exige transformações sociais estruturais urgentes" (CALDART, 2011, p. 152).

Considerando o papel da educação para a superação da relação hierárquica e desigual entre campo e cidade e visando a garantia de direitos, as reivindicações passaram a pautar a presença da Educação do Campo desde a Educação Básica até o Ensino Superior, cujos princípios perpassem questões como o desenvolvimento sustentável, a agricultura familiar camponesa, a Reforma Agrária e a formação específica de professores para atuarem nas áreas rurais.

Nesse percurso, foram criadas em 2007 quatro experiências-piloto de cursos de Licenciaturas em Educação do Campo, ofertadas a partir do Programa de Apoio à Formação Superior em Licenciatura em Educação do Campo (MOLINA, 2017).

Revista Devir Educação, Lavras, vol.5, n2., p.104-125 jul./dez., 2021. 


\section{OO DEVIR EDUCAÇÃO}

ISSN: 2526-849X

A Licenciatura em Educação do Campo tem como princípios a formação multidisciplinar por área de conhecimento e em alternância de tempos e espaços formativos, a intrínseca articulação entre escola e comunidade, a auto-organização discente junto com a gestão compartilhada do curso, congregando docentes, estudantes e membros dos movimentos sociais do campo, inclusive nas instâncias decisórias desta graduação.

Na Universidade Federal do Espírito Santo (UFES), o curso foi criado em 2013 nos campi de Goiabeiras, em Vitória; e São Mateus, norte do Espírito Santo, após longos processos de discussão de sua proposta pedagógica. Em Goiabeiras, objeto de estudo desta pesquisa, o curso iniciou suas atividades acadêmicas no Centro de Educação no ano de 2014, ofertando habilitações nas áreas de Linguagens (Língua Portuguesa, Artes, Literatura e Educação Física) e Ciências Humanas e Sociais (História, Geografia, Sociologia e Filosofia).

A Licenciatura em Educação do Campo - campus Goiabeiras da UFES tem como objetivos específicos:

a. Formar e habilitar profissionais em exercício docente nos anos finais do ensino fundamental e no ensino médio que ainda não possuam a titulação mínima exigida pela legislação educacional em vigor. b. Habilitar professores para a docência multidisciplinar em escolas do campo nas seguintes áreas do conhecimento: Linguagens (Língua Portuguesa, Artes e Literatura e Educação Física); e Ciências Humanas e Sociais. c. Formar educadores para atuar na Educação Básica em escolas do campo, aptos a fazer a gestão de processos educativos e a desenvolver estratégias pedagógicas que visem a formação de sujeitos humanos autônomos e criativos, capazes de produzir soluções para questões inerentes à sua realidade, vinculadas à construção de um projeto de desenvolvimento sustentável do campo e do país. d. Preparar educadores e educadoras para a implantação de escolas públicas de Educação Básica de nível médio e de educação profissional nas/das comunidades camponesas. e. Formar docentes para uma atuação pedagógica transdisciplinar e articuladora das diferentes dimensões da formação humana. f. Garantir reflexões/elaboração pedagógica específica sobre a educação para o trabalho, a educação técnica, tecnológica e científica a ser desenvolvida especialmente na Educação Básica de nível médio e nos anos finais da educação fundamental (UFES, 2014, p. 10).

Com duração de quatro anos e calendário diferenciado, o curso organiza-se em alternância de tempos e espaços que se complementam: o Tempo-Universidade (TU), realizado no campus universitário, correspondendo a 50\% da carga horária, e o TempoComunidade (TC), que refere-se aos outros $50 \%$ e ocorre nas comunidades dos estudantes, vinculando tempos, espaços, teorias, práticas e saberes nessa formação. Assim, tanto os estudantes se deslocam mensalmente para a UFES como os docentes viajam, na medida do 


\section{OO DEVIR EDUCAÇÃO}

ISSN: 2526-849X

possível, até as comunidades dos discentes para visitar as escolas do campo, realizar seminários e demais atividades referentes ao curso.

Nos primeiros quatro anos, o campus Goiabeiras ofertou 440 vagas para as duas habilitações do curso, por meio das quais ingressaram 354 estudantes, residentes em diversos municípios do Espírito Santo e de Minas Gerais. Nessa trajetória, percebemos um número considerável de estudantes que descontinuaram seus estudos logo nos primeiros semestres letivos, o que despertou as inquietações coletivas que levaram ao desenvolvimento desta pesquisa.

De acordo com dados ${ }^{3}$ do Sistema de Informação para o Ensino (SIE) da UFES, referentes aos registros entre os anos de 2014 e 2018, 28 estudantes desistiram facultativamente de suas matrículas, 39 foram desligados por abandono ${ }^{4}$ - sendo 34 somente no ano de 2018 - e 1 estudante fez reopção ${ }^{5}$ de curso. Ou seja, até a colação de grau da primeira turma, 19,2\% dos estudantes não estavam mais matriculados no curso. Ademais, no primeiro semestre de 2018, 42 estudantes já não frequentavam as atividades acadêmicas, embora ainda estivessem matriculados.

Esse levantamento aponta a urgência do debate sobre a permanência estudantil no curso, tornando intrigante o estudo dos motivos que têm levado os discentes a descontinuarem seus estudos, especialmente por conta das especificidades desta Licenciatura. Por tratar-se de uma pesquisa de mestrado profissional que prevê, ainda, a apresentação de um produto relacionado ao estudo desenvolvido, buscamos compreender junto aos estudantes as causas motivadoras da evasão para, coletivamente, propor ações que contribuam para o enfrentamento desta realidade e atuem na garantia da permanência, cujo resultado está elencado nos quadros 1 e 2.

\section{Reflexões sobre a evasão e a permanência no contexto do ingresso das classes populares no Ensino Superior}

Segundo pesquisa realizada pela Associação Nacional dos Dirigentes de Instituições Federais de Ensino Superior e pelo Fórum Nacional de Pró-reitores de Assuntos Comunitários

\footnotetext{
${ }^{3}$ Dados extraídos em fevereiro de 2019.

${ }^{4}$ Segundo a Resolução n ${ }^{\circ}$ 68/2017 do Conselho de Ensino, Pesquisa e Extensão da UFES, é considerado abandono a situação em que o discente não efetua matrícula durante um semestre letivo.

${ }^{5}$ Modalidade destinada aos estudantes que desejam mudar de curso.
} 


\section{OO DEVIR EDUCAÇÃO}

ISSN: 2526-849X

e Estudantis, em 2018, o percentual de estudantes inseridos na faixa de renda mensal familiar per capita de até 1,5 salário mínimo somava 70,2\% (ANDIFES/FONAPRACE, 2019). Ou seja, pouco a pouco, o perfil discente no Ensino Superior tem se aproximado da diversidade cultural, racial e de gênero, bem como da desigualdade de renda do país.

Contudo, o ingresso desses estudantes desafia as instituições a também garantir a permanência, a aprendizagem significativa e aconclusão do curso, principalmente nos campi universitários, espaços marcados por uma cultura elitista e seletiva.

Nesse trajeto, nos deparamos com a evasão e seus diversos entendimentos e implicações. Segundo Relatório da Comissão Especial de Estudos sobre Evasão nas Universidades Públicas Brasileiras, entende-se por evadido o estudante que "deixou o curso sem concluí-lo" (BRASIL, 1996, on-line). O documento explicita ainda a existência de três modalidades principais de evasão no ensino superior.

evasão de curso: quando o estudante desliga-se do curso superior em situações diversas tais como: abandono (deixa de matricular-se), desistência (oficial), transferência ou reopção (mudança de curso), exclusão por norma institucional; evasão da instituição: quando o estudante desliga-se da instituição na qual está matriculado; evasão do sistema: quanto o estudante abandona de forma definitiva ou temporária o ensino superior (BRASIL, 1996, on-line, grifo nosso).

Bueno (apud BRASIL, 1996, on-line) diferencia os conceitos de evasão e "exclusão". Para o autor, a exclusão "implica a admissão de uma responsabilidade da escola e de tudo que a cerca por não ter mecanismos de aproveitamento e direcionamento do jovem que se apresenta para uma formação profissionalizante", enquanto a evasão corresponde "a uma postura ativa do aluno que decide desligar-se por sua própria responsabilidade" (BUENO apud BRASIL, 1996, on-line).

Nessa separação, Bueno ressalta a participação da instituição, do sistema de Ensino Superior e do entorno social no processo de evasão discente, problematizando os limites entre a responsabilidade institucional e individual, ou o que Freire (2001, p. 35) elenca como razões “internas e externas à escola, que explicam a 'expulsão' e a reprovação dos meninos populares".

Seguindo esse caminho, Moehlecke (2007) traz à tona o questionamento a respeito da responsabilidade institucional no processo de evasão. De acordo com a autora, "a evasão por motivo de trabalho foi interpretada em muitos estudos como uma decisão e escolha do aluno, 


\section{OO DEVIR EDUCAÇÃO}

ISSN: 2526-849X

nem sempre se questionando o modo como a instituição, pela sua própria forma de organização, privilegia determinado perfil de aluno, dificultando a permanência de outros" (MOEHLECKE, 2007, p. 2).

Ao refletir sobre a evasão na Educação Básica, Freire (2001) trabalha com o termo “expulsão escolar”, apontando que a saída da escola não caracteriza um ato voluntário do estudante, mas imposto devido às condições adversas presentes dentro e fora dos muros escolares e que interferem no processo de ensino e aprendizagem. $\mathrm{O}$ autor defende que

as crianças populares brasileiras são expulsas da escola - não, obviamente, porque esta ou aquela professora, por uma questão de pura antipatia pessoal, expulse estes ou aqueles alunos ou os reprove. É a estrutura mesmo da sociedade que cria uma série de impasses e de dificuldades, uns em solidariedade com os outros, de que resultam obstáculos enormes para as crianças populares não só chegarem à escola, mas também, quando chegam, nela ficarem e nela fazerem o percurso a que têm direito (FREIRE, 2001, p. 35 , grifo do autor).

Apesar do educador referir-se ao contexto da Educação Básica, entendemos que esta análise pode ser aplicada no Ensino Superior brasileiro, pois, guardadas as diferenças de cada etapa e do público-alvo a que se destinam, a evasão é um problema que atinge a todos os níveis educacionais do mundo contemporâneo e cujas motivações tendem a aproximar-se.

Logo, considerando as pesquisas já realizadas sobre a temática, aliadas à perspectiva teórica adotada neste estudo, percebemos que a evasão pode resultar de uma decisão do estudante ou de uma combinação de fatores institucionais, escolares, sociais, econômicos e pessoais, o que caracterizamos como expulsão, seguindo a proposição de Freire (2001). Ou seja, o estudante, nessa última hipótese, é expulso em consequência de uma série de motivações que dificultam sua permanência e que estão alheias à sua vontade ou possibilidade de resolução.

Assim, corroboramos com a interpretação de Freire (2001) sobre a concepção de expulsão escolar por acreditarmos que as motivações para a descontinuidade dos estudos estão relacionadas à existência de fatores internos e externos à instituição, podendo dificultar e impossibilitar a permanência estudantil.

Em relação às possíveis causas para explicar a evasão no Ensino Superior, Moehlecke (2007, p. 5) elenca em três grupos os fatores individuais e institucionais: "a) aqueles que se relacionam ao próprio estudante e suas escolhas; b) os relacionados ao curso e/ou à instituição; c) os relacionados a fatores sócio-culturais e econômicos externos".

Revista Devir Educação, Lavras, vol.5, n2., p.104-125 jul./dez., 2021. 


\section{OO DEVIR EDUCAÇÃO}

ISSN: 2526-849X

Sobre os fatores individuais, a autora destaca a incerteza quanto ao curso, motivos familiares como doença e questões financeiras e a necessidade de trabalhar. Já no rol de motivações institucionais, Moehlecke (2007, p. 13) enumera “[...] desilusão com o curso; problemas relacionados ao curso como currículo (muito rígido, inadequado para o aluno trabalhador), ao relacionamento com professores, com colegas, funcionários; dificuldade de acesso à instituição".

Veloso e Almeida (2002) evidenciam a dificuldade dos estudantes da classe trabalhadora em conciliar estudo e trabalho por conta da necessidade de exercerem atividades remuneradas para sustentar os gastos com os cursos e/ou contribuir para a renda familiar.

Nas licenciaturas, estudos apontam que estas consistem em um dos grandes desafios para o combate à evasão no Ensino Superior. Carvalho e Oliveira (apud GILIOLI, 2016, p. 15) constatam que "[...] por todo o Brasil, as universidades apresentam alto índice de evasão nos setores de licenciatura (48\% não chegam a se formar, todo ano 19,6\% desistem do curso)". Os autores destacam ainda a falta de perspectiva na área devido à desvalorização da profissão de professor como fator de evasão nas licenciaturas.

Sobre a qualidade da ampliação do acesso ao Ensino Superior, Molina (2015) analisa que o investimento público tem sido insuficiente. Nesse mesmo caminho, Mancebo et al. discute a inexistência de garantias de qualidade.

[...] a contrapartida financeira tem sido insuficiente, de modo que a expansão da rede pública federal tem ocorrido com forte racionalização de recursos humanos e tem remetido à precarização e intensificação do trabalho docente, configurando uma expansão sem garantias de qualidade que longe de corrigir a distribuição desigual dos bens educacionais, tende a aprofundar as condições históricas de uma educação superior elitista e excludente (MANCEBO et al. apud MOLINA, 2015, p. 148).

Portanto, democratizar o ensino para as classes camponesas significa ainda, incorporar, implementar e respeitar, dentre as políticas de ações afirmativas implantadas, as prerrogativas da Educação do Campo tanto no que diz respeito ao acesso quanto à permanência.

Na Licenciatura em Educação do Campo da UFES, o ingresso se dá por edital de seleção próprio, respeitando as especificidades do curso e dos seus sujeitos. Em função da organização curricular em alternância, o curso oferta mecanismos de assistência estudantil durante as atividades desenvolvidas no campus Goiabeiras, como o custeamento de 


\section{OO DEVIR EDUCAÇÃO}

ISSN: 2526-849X

alimentação para todos os discentes e hospedagem e transporte para aqueles que residem fora da Região Metropolitana da Grande Vitória, uma vez que a universidade não possui alojamento, apesar desta também ser uma reivindicação para esta Licenciatura. Além disso, é prevista a sistematização da Ciranda Infantil, conforme discutiremos adiante, para garantir que pais e mães possam estudar enquanto seus filhos são cuidados de forma responsável e pedagógica no campus.

Entendemos, então, que o não atendimento às demandas da classe camponesa refletiria apenas o cumprimento do que determinam os instrumentos normativos quanto à criação de vagas, não democratizando, de fato, o acesso ao Ensino Superior a essa parcela da população e fragilizando sua permanência.

\section{A proposta metodológica}

Este estudo emergiu com o objetivo geral de compreender os motivos que têm impossibilitado a permanência discente na Licenciatura em Educação do Campo - campus Goiabeiras da UFES e propor instrumentos, ações e/ou políticas de enfrentamento, apresentados enquanto produto desta pesquisa de mestrado profissional.

Tendo em vista que uma pesquisa crítica implica "[...] na recusa dos mitos da neutralidade e da objetividade e obriga o pesquisador a assumir plenamente uma vontade e uma intencionalidade políticas" (OLIVEIRA; OLIVEIRA, 1985, p. 25), e considerando que neste estudo buscamos ir ao encontro do que Freire (2017) aponta sobre a valorização e o respeito da sabedoria popular e de seus sujeitos enquanto agentes potenciais no processo de emancipação, nos propusemos a realizar a pesquisa participante. De acordo com Gil, a pesquisa participante "deseja colocar-se a serviço dos oprimidos e necessita identificar com clareza quem são eles no âmbito de uma 'comunidade"” (2002, p. 150).

A produção dos dados apresentados neste artigo teve o suporte de pesquisa bibliográfica, investigação documental e pesquisa de campo, que ocorreu em 2018 e contou com a aplicação de questionário junto aos estudantes que ainda frequentavam o curso; houve também a realização de entrevistas coletivas com aqueles que apontaram em questionário a motivação em descontinuar seus estudos e foram feitas análises compartilhadas com os estudantes que participaram dessas entrevistas, para a discussão coletiva do material.

Revista Devir Educação, Lavras, vol.5, n2., p.104-125 jul./dez., 2021. 


\section{OO DEVIR EDUCAÇÃO}

ISSN: 2526-849X

Entendendo que "a participação popular comunitária deve se dar, preferencialmente, através de todo o processo de investigação-educação-ação", e que "uma verdadeira pesquisa participante cria solidariamente, mas nunca impõe partidariamente conhecimentos e valores" (BRANDÃO; BORGES, 2007, p. 55, grifos dos autores), ou seja, que a pesquisa participante deve caracterizar-se como um processo de criação social de conhecimento, destacamos as entrevistas coletivas e análises compartilhadas pela riqueza dos dados produzidos e pelos desafios enfrentados. Nesses espaços, os estudantes apontaram possíveis caminhos para a garantia da permanência no curso, revelando a importância da busca pela emancipação, criticidade e diretividade da educação na formação desses sujeitos.

Ao todo, 143 estudantes responderam o questionário, dos quais 74 foram convidados para participar das entrevistas coletivas por terem apontado neste instrumento a possibilidade de sair do curso. Destes, 33 estudantes participaram das entrevistas coletivas e 23 retornaram para as análises compartilhadas.

Tanto as entrevistas coletivas quanto as análises compartilhadas foram realizadas pessoalmente, gravadas em áudio e transcritas respeitando os modos de fala dos envolvidos. Além disso, visando o sigilo da identidade dos participantes e o comprometimento ético ${ }^{6}$, utilizamos nomes fictícios na apresentação dos dados.

A análise do material ocorreu a partir da tabulação dos dados, identificação das categorias que emergiram com maior frequência nos relatos dos estudantes e análise de conteúdo, em que para Bardin "os resultados brutos são tratados de maneira a serem significativos (falantes) e válidos" (1977, p. 101).

Assim como as demais etapas da pesquisa que objetivaram atender aos princípios da pesquisa participante e da educação popular emancipatória de Freire (2017), a pré-análise dos dados e a exploração do material foram realizadas de forma compartilhada e dialogada com os envolvidos.

Do ponto de vista metodológico, a investigação que, desde o seu início, se baseia na relação simpática de que falamos, tem mais esta dimensão fundamental para a sua segurança - a presença crítica de representantes do povo desde o seu começo até sua fase final, a da análise da temática encontrada, que se prolonga na organização do conteúdo programático da ação educativa, como ação cultural libertadora (FREIRE, 2017, p. 156).

\footnotetext{
${ }^{6}$ A pesquisa foi aprovada pelo Comitê de Ética em Pesquisa da UFES, conforme os pareceres consubstanciados $\mathrm{n}^{\mathrm{o}}$ 2.650.976, de 11 de maio de 2018, e 3.295.106, de 30 de abril de 2019 .
}

Revista Devir Educação, Lavras, vol.5, n2., p.104-125 jul./dez., 2021. 


\section{OO DEVIR EDUCAÇÃO}

ISSN: 2526-849X

Após a exploração do material, do tratamento e da interpretação dos dados à luz dos referenciais teóricos, procuramos junto aos envolvidos compreender os desafios da permanência estudantil no curso para, então, propor ações de enfrentamento.

\section{O que encontramos no trajeto e quais as possibilidades para a transformação}

A partir da análise do compartilhamento de conhecimentos, questionamentos e vivências alguns caminhos mostraram-se fecundos, permitindo proposições coletivas para o enfrentamento da evasão e fornecendo subsídios para atuação da coordenação do curso, articulada com as demais unidades estratégicas da UFES, a fim de garantir a permanência estudantil nesta Licenciatura.

Neste processo emergiram dez categorias de análise. Para melhor entendimento dos diversos fatores que interferem na permanência estudantil no curso, visto a evasão ter se caracterizado como um fenômeno multifatorial, subdividimos as categorias em duas dimensões atuantes: a dos desafios da permanência ligados a fatores internos à Licenciatura em Educação do Campo e a dos desafios da permanência relacionados a fatores externos.

Dentre os fatores internos estão os desafios relacionados ao funcionamento e demandas acadêmicas do curso, bem como a relação deste com seus sujeitos, isto é, o relacionamento entre docentes e discentes, as atividades propostas, os impactos do calendário acadêmico diferenciado e a participação estudantil nos espaços coletivos de discussão.

Já os fatores externos são caracterizados por aqueles de ordem pessoal ou emocional, incluídas aí questões familiares e laborais, características da vida privada, mas que são vistas pelos sujeitos da Educação do Campo como articuladas.

Os quadros 1 e 2 reúnem de forma sistematizada o resultado que chegamos, elencando as categorias, ou seja, as causas que desafiam a permanência estudantil na Licenciatura em Educação do Campo, dispostas em ordem decrescente de recorrência e intensidade em que apareceram nas falas discentes e em interlocução com suas respectivas subcausas desdobramentos que se manifestaram nas categorias - e possíveis estratégias para superação.

Quadro 1 - Síntese de ações para enfrentar a evasão referente aos fatores internos - Vitória - 2019.

\begin{tabular}{|c|c|c|}
\hline Causas & Subcausas & Ações de enfrentamento \\
\hline & & Detalhar edital de seleção e produzir informativo com \\
\hline
\end{tabular}

Revista Devir Educação, Lavras, vol.5, n2., p.104-125 jul./dez., 2021. 


\begin{tabular}{|c|c|c|}
\hline \multirow[t]{2}{*}{$\begin{array}{l}\text { Desconhecimento } \\
\text { dos sujeitos sobre } \\
\text { o curso }\end{array}$} & $\begin{array}{l}\text { Desconhecimento dos } \\
\text { estudantes }\end{array}$ & $\begin{array}{l}\text { orientações sobre o curso; manter o site do curso atualizado; } \\
\text { realizar palestras sobre o curso nas cidades do interior do } \\
\text { estado; promover momentos explicativos antes da matrícula } \\
\text { entre a coordenação e os ingressantes; realizar entrevistas } \\
\text { individuais com os ingressantes e aplicar questionário de } \\
\text { disponibilidade; dialogar com líderes dos movimentos sociais } \\
\text { matriculados no curso para que trabalhem na acolhida discente, } \\
\text { a desconstrução de ideias preconceituosas e o esclarecimento } \\
\text { das práticas do curso. }\end{array}$ \\
\hline & $\begin{array}{l}\text { Desconhecimento dos } \\
\text { docentes }\end{array}$ & $\begin{array}{l}\text { Detalhar edital de concurso para docentes; promover o } \\
\text { fortalecimento do coletivo docente com a ampliação na } \\
\text { participação em grupos de estudos sobre a Educação do Campo, } \\
\text { em reuniões pedagógicas e demais atividades. }\end{array}$ \\
\hline \multirow[t]{2}{*}{$\begin{array}{l}\text { Tensões e } \\
\text { conflitos internos } \\
\text { entre estudantes e } \\
\text { professores }\end{array}$} & $\begin{array}{l}\text { Conflitos entre } \\
\text { estudantes e docentes }\end{array}$ & $\begin{array}{l}\text { Promover reuniões pedagógicas ampliadas para que os } \\
\text { estudantes sejam sujeitos pedagógicos do curso, sendo este um } \\
\text { espaço de vazão dos conflitos e possibilidade de resoluções; } \\
\text { disponibilidade para o diálogo e olhar pedagógico atento às } \\
\text { especificidades do curso e dos seus sujeitos; ampliar a } \\
\text { participação docente nas atividades de acolhida discente e nas } \\
\text { apresentações de Trabalho de Conclusão de Curso (TCC); } \\
\text { sistematização de formação continuada para os docentes. }\end{array}$ \\
\hline & $\begin{array}{l}\text { Conflitos entre os } \\
\text { estudantes }\end{array}$ & $\begin{array}{l}\text { Promover atividades culturais e de integração discente (serões); } \\
\text { fomentar a sistematização da auto-organização estudantil. }\end{array}$ \\
\hline \multirow{2}{*}{$\begin{array}{l}\text { Dificuldades na } \\
\text { realização das } \\
\text { atividades }\end{array}$} & $\begin{array}{l}\text { Rotina laboral } \\
\text { exaustiva }\end{array}$ & \multirow{2}{*}{$\begin{array}{c}\text { Aplicar questionário socioeconômico e ocupacional aos } \\
\text { estudantes para mapear a ocupação laboral e sua influência no } \\
\text { desempenho acadêmico; buscar entendimento tanto da UFES } \\
\text { quanto dos docentes do curso para as especificidades } \\
\text { educacionais da classe trabalhadora, a fim de que sejam } \\
\text { traçadas propostas pedagógicas populares direcionadas a suas } \\
\text { necessidades; garantir momentos específicos de orientação de } \\
\text { estudos. }\end{array}$} \\
\hline & $\begin{array}{l}\text { Não compreensão das } \\
\text { atividades solicitadas }\end{array}$ & \\
\hline \multirow{2}{*}{$\begin{array}{l}\text { Calendário } \\
\text { acadêmico }\end{array}$} & $\begin{array}{l}\text { Contrariedade no } \\
\text { sentimento discente } \\
\text { de pertencimento à } \\
\text { Universidade }\end{array}$ & \multirow{2}{*}{$\begin{array}{l}\text { Realizar momentos explicativos antes da matrícula, reforçando } \\
\text { que o calendário diferenciado sem aulas diárias visa possibilitar } \\
\text { que a classe popular camponesa possa trabalhar e estudar; } \\
\text { avaliar constantemente com o coletivo deste curso a eficácia do } \\
\text { calendário diferenciado na manutenção da permanência } \\
\text { estudantil. }\end{array}$} \\
\hline & $\begin{array}{l}\text { Desgaste em relação } \\
\text { à jornada acadêmica } \\
\text { durante o Tempo- } \\
\text { Universidade }\end{array}$ & \\
\hline \multirow[b]{2}{*}{$\begin{array}{l}\text { O silêncio } \\
\text { discente }\end{array}$} & $\begin{array}{l}\text { Nos espaços de } \\
\text { gestão compartilhada }\end{array}$ & $\begin{array}{l}\text { Fomentar junto aos discentes, propostas de auto-organização } \\
\text { mais acolhedoras, apostando no diálogo. }\end{array}$ \\
\hline & $\begin{array}{l}\text { Na comunicação } \\
\text { interpessoal no } \\
\text { momento de decisão } \\
\text { pela saída do curso }\end{array}$ & $\begin{array}{l}\text { Criar redes de apoio no curso, formadas por pessoas eleitas para } \\
\text { atuarem nesse tipo de situação, buscando possibilidades de } \\
\text { resolução junto à coordenação. }\end{array}$ \\
\hline
\end{tabular}

Fonte: Do autor (2019).

Quadro 2 - Síntese de ações para enfrentar a evasão referente aos fatores externos - Vitória - 2019.

Revista Devir Educação, Lavras, vol.5, n2., p.104-125 jul./dez., 2021. 


\section{OO DEVIR EDUCAÇÃO}

ISSN: 2526-849X

\begin{tabular}{|c|c|c|}
\hline Causas & Subcausas & Ações de enfrentamento \\
\hline \multirow[t]{2}{*}{ Trabalho } & $\begin{array}{c}\text { Resistência das } \\
\text { secretarias de } \\
\text { Educação em liberar } \\
\text { os profissionais de } \\
\text { suas atividades } \\
\text { laborais para } \\
\text { cursarem esta } \\
\text { Licenciatura }\end{array}$ & $\begin{array}{l}\text { Promover interação entre as secretarias municipais, Secretaria } \\
\text { Estadual de Educação (Sedu) e a UFES, inicialmente por meio } \\
\text { de reuniões explicativas sobre o curso, suas demandas e } \\
\text { especificidades, visando combater a resistência por } \\
\text { desconhecimento. }\end{array}$ \\
\hline & $\begin{array}{l}\text { Dificuldade em } \\
\text { administrar vínculos } \\
\text { empregatícios com as } \\
\text { demandas do curso }\end{array}$ & $\begin{array}{l}\text { Realizar momentos explicativos antes da matrícula, destacando } \\
\text { o que é a formação em alternância, como se desenvolve e sua } \\
\text { implicação na organização do calendário acadêmico. }\end{array}$ \\
\hline \multirow[t]{2}{*}{ Família } & $\begin{array}{l}\text { Estudantes, pais e } \\
\text { mães que precisam } \\
\text { levar os filhos para o } \\
\text { Tempo-Universidade }\end{array}$ & $\begin{array}{l}\text { Sistematizar a Ciranda Infantil junto aos estudantes, buscando } \\
\text { auxílio da UFES na oferta de espaços adequados, materiais de } \\
\text { higiene e apoio e disponibilização de pessoal capacitado para } \\
\text { estar com as crianças de forma pedagógica e responsável. }\end{array}$ \\
\hline & $\begin{array}{l}\text { Machismo e } \\
\text { patriarcado }\end{array}$ & $\begin{array}{c}\text { Criar redes de apoio e reflexão como possibilidade de } \\
\text { mediação. }\end{array}$ \\
\hline $\begin{array}{l}\text { Não } \\
\text { reconhecimento } \\
\text { do poder público }\end{array}$ & $\begin{array}{l}\text { Preocupação discente } \\
\text { com o futuro } \\
\text { profissional }\end{array}$ & $\begin{array}{l}\text { Manter e ampliar as ações desenvolvidas pela coordenação do } \\
\text { curso em relação ao diálogo com a Sedu e a União Nacional dos } \\
\text { Dirigentes Municipais de Educação (Undime) para buscar } \\
\text { reconhecimento. }\end{array}$ \\
\hline $\begin{array}{l}\text { Recursos } \\
\text { financeiros }\end{array}$ & & $\begin{array}{c}\text { Aplicar questionário socioeconômico e ocupacional buscando } \\
\text { compreender como os recursos financeiros interferem na vida } \\
\text { acadêmica e, posteriormente, propor ações direcionadas; } \\
\text { gerenciar bolsas estudantis priorizando discentes em } \\
\text { vulnerabilidade socioeconômica. }\end{array}$ \\
\hline \multirow{3}{*}{$\begin{array}{l}\text { Preconceito em } \\
\text { relação ao curso e } \\
\quad \text { seus sujeitos }\end{array}$} & $\begin{array}{c}\text { Preconceito dos } \\
\text { profissionais com } \\
\text { quem os estudantes } \\
\text { trabalham em relação } \\
\text { à formação na } \\
\text { Licenciatura em } \\
\text { Educação do Campo }\end{array}$ & $\begin{array}{c}\text { Promover conhecimento crítico sobre o curso, por meio de } \\
\text { ações dialógicas de interação entre a Sedu, a Undime e } \\
\text { secretarias municipais de Educação, conforme destacado nas } \\
\text { categorias “Trabalho" e "Não reconhecimento do poder } \\
\text { público". }\end{array}$ \\
\hline & $\begin{array}{l}\text { Preconceito dos } \\
\text { docentes do curso } \\
\text { sobre a formação } \\
\text { ofertada }\end{array}$ & $\begin{array}{c}\text { Por articular-se com a categoria "Desconhecimento dos sujeitos } \\
\text { sobre o curso", propomos as mesmas ações. }\end{array}$ \\
\hline & $\begin{array}{l}\text { Preconceito de outros } \\
\text { sujeitos da } \\
\text { Universidade em } \\
\text { relação à formação } \\
\text { no curso }\end{array}$ & $\begin{array}{l}\text { Estreitar relações entre as demais instâncias da UFES e o curso, } \\
\text { com a participação em atividades acadêmicas, eventos e demais } \\
\text { ações que possibilitem maior conhecimento dos princípios desta } \\
\text { Licenciatura. }\end{array}$ \\
\hline
\end{tabular}

Fonte: Do autor (2019).

Salientamos que as ações de enfrentamento propostas surgiram dos próprios estudantes, de atividades realizadas pela coordenação do curso e de indicações pensadas 


\section{OO DEVIR EDUCAÇÃO}

ISSN: 2526-849X

mediante análise dos dados. Isto posto, discutiremos algumas dessas ações em desenvolvimento ou já realizadas, refletindo o caráter dinâmico desta graduação e o olhar atento dos envolvidos frente às necessidades da classe camponesa.

O Desconhecimento dos sujeitos sobre o curso foi o principal desafio apontado referente aos fatores internos à Licenciatura em Educação do Campo. Nesta categoria chama a atenção o fato de que, dos 33 participantes das entrevistas coletivas, 14 afirmaram não ter conhecimento sobre esta Licenciatura e seus princípios, 11 relataram ter pouco conhecimento, 7 mostraram conhecer de forma geral o curso, principalmente a respeito da proposta da Educação do Campo e sua formação de caráter político e popular vinculada aos movimentos sociais, e 1 discente não respondeu.

Em se tratando das características deste curso os dados surpreendem, pois, para ingressar os discentes passam por processo seletivo específico, o que denotaria que a escolha pela Licenciatura em Educação do Campo ter-se-ia dado por opção política e até mesmo pelo viés da militância, não havendo espaço para desconhecimento. Contudo, não é o que os relatos apontam.

Eu cheguei não sabia muito o que era, o que tinha que fazer, se formar para quê. Aí que veio professor. Eu nunca quis ser professora. Meu sonho era ser veterinária, agrônoma, qualquer coisa, menos professora. Aí foi quando passou na minha cabeça em desistir (Daniela).

Eu acredito que o curso está no caminho certo, o ruim é que as pessoas que não estão no lugar certo no curso, entendeu? Às vezes pode ter entrado, assim, por uma má informação no edital, entendeu, não ter se informado direito, aí acaba desistindo ao longo do caminho, e deixando vago (João).

Frente a essa realidade, a coordenação iniciou, em 2018, uma discussão sobre a realização de um momento de diálogo aprofundado com os aprovados no processo seletivo daquele ano, junto com a pesquisadora e servidores da Secretaria Integrada que atendem ao curso. Esta etapa, sugerida pelos estudantes, ocorreria antes da matrícula e possibilitaria que fossem apresentadas e discutidas as concepções do curso, o perfil do egresso que se busca formar, a organização em alternância, o calendário acadêmico diferenciado, a vinculação com os movimentos sociais, a perspectiva crítica e política desta graduação, questões de ordem prática relacionadas à Secretaria, entre outras temáticas que poderiam surgir.

Com este diálogo, esperava-se esclarecer as principais dúvidas de forma que fossem matriculados aqueles que de fato desejassem assumir um compromisso com esta graduação, considerando o papel que deverão desempenhar não somente enquanto estudantes da 


\section{OO DEVIR EDUCAÇÃO}

ISSN: 2526-849X

Licenciatura em Educação do Campo, mas, principalmente, como educadores deste projeto de transformação social, na tentativa de reduzir a descontinuidade pelo desconhecimento. Todavia, mesmo após vários contatos com a Pró-Reitoria de Graduação (Prograd) e sinalizada a necessidade deste encontro, o planejamento não foi colocado em prática pois o edital de convocação para matrícula não previu em seu cronograma organização necessária para atender esta solicitação.

Ainda assim, em reunião do Colegiado do curso foram traçados novos encaminhamentos para garantir este espaço, com a solicitação do envio, por e-mail, de um texto produzido pela coordenação explicando o funcionamento desta graduação e convidando os aprovados para um momento dialógico no dia da matrícula, em que seriam colhidas, ainda, informações necessárias para a organização interna da Secretaria no que diz respeito à hospedagem, alimentação e transporte dos futuros discentes.

Todavia, essas informações não chegaram a todos e este momento não ocorreu com o coletivo, fragilizando as ações sistematizadas. O ocorrido reforça a necessidade de entendimento da universidade sobre a complexa dinâmica acadêmica e administrativa deste curso, bem como a importância do alinhamento entre coordenação e Prograd no que diz respeito à elaboração dos editais de seleção e matrícula e estabelecimento de cronogramas que dialoguem com a realidade desta Licenciatura, uma vez que o desconhecimento no momento do ingresso mostrou-se determinante na descontinuidade dos estudos no curso.

Esta não foi a primeira vez em que não foi possível realizar este momento junto aos aprovados, fato que é analisado pelo estudante Bruno.

O problema é que a gente vai sentindo uma expectativa negativa que o curso vai acabar. Já reduzimos o tamanho das turmas, já reduzimos o processo seletivo. Então tá uma preocupação que as evasões são muito grandes. [...] Nós já discutimos aqui na Licenciatura que antes da turma, antes da turma fazer a matrícula [inaudível], deveria ter uma reunião com os estudantes pra falar do curso, pra falar o que é o curso. E isso não se conseguiu fazer antes do processo seletivo, antes da matrícula da turma que está no segundo período. A gente tem que insistir nesse processo. Apresentar a Licenciatura, seus problemas, suas dificuldades, suas vantagens, as coisas boas, as coisas, vamos dizer assim, mais dificultosas. Entrou, já sabe o que que vai encontrar, pelo menos aparentemente tem uma ideia do que vai encontrar (Bruno).

Em relação ao desconhecimento docente e à necessidade de fortalecimento do coletivo de professores do curso, em 2015, foi criado o Grupo de Estudos e Pesquisas em Educação do 


\section{OO DEVIR EDUCAÇÃO}

ISSN: 2526-849X

Campo do Espírito Santo (Gepeces), com a finalidade de discutir a Educação do Campo e suas especificidades. Porém, a participação docente neste grupo não se dava a contento, sendo os participantes em sua maioria estudantes de pós-graduação que pesquisam a temática.

Além disso, quinzenalmente, são realizadas reuniões pedagógicas entre coordenação e docentes, onde são debatidas questões pertinentes ao curso e propostos encaminhamentos. Por um período ocorreram reuniões que contavam também com a presença de estudantes e representantes dos movimentos sociais, para que fossem pensadas as questões pedagógicas desta graduação. Entretanto, parte do corpo docente não concordava com a participação estudantil em reuniões pedagógicas e poucos aderiram à proposta. Por isso, essas reuniões passaram a ocorrer apenas entre os professores. Importante salientar que, assim como no Gepeces, a participação docente nesses espaços não se dava de forma satisfatória. Somente a partir de 2018, a presença dos professores foi fortalecida, principalmente com o ingresso de novos docentes, possibilitando um diálogo mais aprofundado.

Da mesma forma, eventos, apresentações de TCC e outras atividades fomentadas pelo curso não contam com a presença de parte considerável dos docentes, ausência que é notada pelos discentes.

E a acolhida por parte dos professores, não adianta os professores achar, assim, que as turmas têm que acolher os alunos novos. Sim, das turmas também, mas se os professores não dão o exemplo não vai à frente. [...] $\mathrm{E}$ não é só na hora da entrada, na aula inaugural, é por todo o momento (Priscila).

[...] quando a UFES está de férias a gente vê poucos professores prestigiando a apresentação dos TCC's dos alunos que eles inclusive ajudaram na formação. E dos estudantes a mesma coisa. Boa parte dos estudantes não está prestigiando os colegas que estão se formando agora no oitavo período. Uma coisa gera a outra (Bruno).

Os destaques refletem a necessidade do fortalecimento deste coletivo para que o curso se consolide, o que acreditamos que reduziria parte das Tensões e conflitos internos entre estudantes e professores e, inclusive, as Dificuldades na realização das atividades apresentadas por uma classe popular cujas especificidades ainda não são totalmente conhecidas e reconhecidas no Ensino Superior.

Buscar o reconhecimento da Licenciatura em Educação do Campo junto à universidade, o poder público e a sociedade em geral tende a minimizar, ainda, as dificuldades enfrentadas pelos discentes no Trabalho, principalmente no que tange ao Preconceito em relação ao curso e seus sujeitos. A categoria Trabalho, especificamente, surgiu nos 


\section{OO DEVIR EDUCAÇÃO}

ISSN: 2526-849X

questionários como a segunda principal motivação entre os 74 estudantes que afirmaram já terem pensado em sair do curso, citada 25 vezes e estando atrás apenas de fatores relacionados a demandas pessoais. Por esse motivo, esta categoria aparece como a principal causa para a descontinuidade dos estudos relacionada a fatores externos ao curso, gerando inclusive desgastes emocionais, como apontado pelas estudantes Gisele e Alice.

No meu trabalho também é muito estressante, eu tenho que pagar também as horas, além de levar o atestado, eu tenho que pagar as horas dos dias que eu fico aqui, trabalhando depois do expediente dia de sábado. Então, às vezes, é muito cansativo, às vezes dá vontade de desistir (Gisele).

[...] eu tive uma briga danada com a minha diretora e falei que ia colocar o meu secretário de Educação na justiça, porque ele falou que ia cobrar o sábado e o domingo meu, entendeu? (Alice).

Nesse sentido, a coordenação do curso e a direção do Centro de Educação estão em constante diálogo com as Secretarias Municipais e Estadual de Educação e com a Undime, além da realização de visitas às escolas para apresentação desta Licenciatura.

Uma das conquistas desses encontros com o poder público foi a inédita inclusão da possibilidade de contratação de licenciados em Educação do Campo, prevista em editais de processo seletivo publicados em novembro de 2018, por meio da inserção de escolas localizadas em assentamentos, escolas que adotam a alternância e Centros Estaduais Integrados de Educação Rural como áreas de atuação dos profissionais admitidos. Esses avanços são importantes para o reconhecimento não apenas do curso, mas da necessidade do olhar diferenciado para o meio rural brasileiro, e justificam-se em função da demanda latente dos egressos desta Licenciatura por postos de atuação e, principalmente, nas escolas localizadas no campo, que necessitam de profissionais com capacitação que atenda aos seus anseios.

Já a não concretização da Ciranda Infantil foi apontada como um dos entraves à permanência estudantil segundo a categoria Família. Nascida nos assentamentos e acampamentos do Movimento dos Trabalhadores Rurais Sem Terra (MST), a Ciranda Infantil objetiva pensar a educação das crianças de 0 a 6 anos de forma a possibilitar que mães e pais possam estudar enquanto os filhos aprendem, socializam e brincam. Segundo o MST, as Cirandas Infantis "são espaços educativos intencionalmente planejados, nos quais as crianças aprendem, em movimento, a ocupar o seu lugar na organização de que fazem parte. É muito mais que espaços físicos, são espaços de trocas, aprendizados e vivências coletivas" (MST, 2004, p. 25). 


\section{OO DEVIR EDUCAÇÃO}

ISSN: 2526-849X

Em um curso composto majoritariamente por mulheres ${ }^{7}$, a responsabilidade pelos filhos reforça as relações de gênero que ainda atribuem a elas o cuidado da casa e da família, atuando diretamente na condição de permanência destas discentes, conforme relatos de Geórgia e Wanessa.

Eu, assim, não sei nem se eu posso dizer se eu já perdi ou tô perdendo o meu casamento, por causa disso também. Lembrando que eu tenho uma criança especial, que é muito difícil conciliar [...] marido não entende, é ciúme, é tudo. Igual a Antônia falou, é muito complicado a gente conciliar. Eu acho que pros homens é mais fácil, porque a gente que é dona de casa, a gente tem que cozinhar, lavar, fazer tudo, eu dou banho no meu filho, tudo é eu [...] por várias vezes já quase desisti do curso. Eu tô tentando ficar em pé aí, ficar firme aí, porque tá difícil (Geórgia, grifo nosso).

A melhoria de uma possível creche mais montada, entendeu, e sei lá, infraestrutura melhor, pra poder atender melhor essas crianças. A minha por exemplo tá com seis anos, eu consigo deixar ela com alguém, eu pago alguém. Mas se a gente já paga alguém, a gente poderia pagar (Wanessa).

Pensando nisso, a auto-organização estudantil do curso possui a Comissão de Ciranda, que busca criar meios para que as crianças levadas para o Tempo-Universidade (TU) sejam cuidadas de forma responsável e digna. Ou seja, na Licenciatura em Educação do Campo, essa demanda, a princípio pessoal, é abordada como responsabilidade de todo o coletivo.

No TU de janeiro de 2019, por exemplo, foi organizado um espaço com brinquedos e materiais para práticas pedagógicas das crianças. Naquele momento, o Movimento Estudantil Kizomba e o Levante Popular da Juventude cederam cirandeiros voluntários para contribuir com a sistematização do processo, a supervisão e o cuidado das crianças.

Além disso, uma docente do curso é responsável por um projeto de extensão destinado à organização da Ciranda. Entretanto, o diálogo avança lentamente e, até então, as crianças têm sido recebidas na UFES de forma improvisada nas salas de aula.

Percebemos, desse modo, que a classe trabalhadora camponesa não separa a vida em âmbito pessoal, familiar ou laboral, sendo que as diversas dimensões da vida são tratadas de forma articulada, o que justifica a importância dada à Ciranda Infantil neste curso. Por isso, torna-se primordial que a universidade e o Centro de Educação busquem meios para o amadurecimento da Ciranda, ofertando espaços adequados para receber essas crianças e, com

\footnotetext{
${ }^{7}$ De acordo com o SIE, $75 \%$ dos discentes matriculados na época da realização das entrevistas coletivas eram mulheres.
}

Revista Devir Educação, Lavras, vol.5, n2., p.104-125 jul./dez., 2021. 


\section{OO DEVIR EDUCAÇÃO}

ISSN: 2526-849X

isso, possibilitar que a classe trabalhadora, em especial a camponesa, prossiga com os estudos.

Além das ações sinalizadas nos quadros, propomos ainda, três diretrizes que acreditamos que possam contribuir para a permanência estudantil no curso. A primeira dispõe sobre a possível alteração no artigo 53 da Resolução n. ${ }^{\circ}$ 35/2017 do Conselho Universitário da UFES, em que se propõe a inclusão da palavra "camponeses" junto ao grupo prioritário de estudantes atendidos pelo Programa Integrado de Bolsas para Estudantes de Graduação, ficando assim redigido: "na seleção dos bolsistas será dada prioridade aos estudantes pretos, pardos, indígenas e camponeses (PPIC) ou que possuam renda familiar mensal de até 1,5 salário mínimo per capita”.

A segunda proposta surgiu da ausência de projetos destinados exclusivamente para os estudantes deste curso dentre os Projetos de Ensino e do Programa Institucional de Apoio Acadêmico desenvolvidos pela Prograd e pela necessidade de estimular os docentes desta graduação a ofertarem propostas para os sujeitos do campo. Nesse sentido, sugerimos a inclusão desses projetos na pontuação para a progressão docente, com pesos diferenciados em função do trabalho extra que demandam, tendo em vista, a necessidade de serem realizados nas próprias comunidades camponesas. Esta é uma tentativa de contemplar de maneira articulada as necessidades discentes e as condições reais de trabalho e tempo dos docentes.

Já a terceira sugestão trata das exigências previstas para concurso docente, em que propomos a inclusão em edital de pontuação diferenciada para a apresentação de plano de trabalho contendo vínculo não somente com ensino, pesquisa e extensão, mas também com alternância. Dessa forma, busca-se a contratação de docentes que tenham mais proximidade com as especificidades deste curso, objetivando reduzir inclusive as solicitações de mudança ${ }^{8}$ de área de atuação por parte dos professores.

\section{Algumas considerações}

Realizar pesquisa participante enquanto escolha metodológica e política veio ao encontro da necessidade de apresentação de um produto associado ao estudo desenvolvido, como um pressuposto fundamental do mestrado profissional. A possibilidade da

\footnotetext{
${ }^{8}$ O Centro de Educação recebeu até agosto de 2019 dez pedidos de professores que optaram por não fazer parte do corpo docente da Licenciatura em Educação do Campo, apesar dos editais de concurso por meio dos quais ingressaram na UFES explicitarem que as vagas se destinavam a este curso. Destes, $40 \%$ solicitaram a mudança entre os anos de 2017 e 2018.
}

Revista Devir Educação, Lavras, vol.5, n2., p.104-125 jul./dez., 2021. 


\section{OO DEVIR EDUCAÇÃO}

ISSN: 2526-849X

transformação por meio da intervenção, aliada ao compromisso social da UFES enquanto instituição pública de ensino na busca pela permanência e conclusão do curso pelos estudantes, mostrou-se um importante caminho a ser trilhado coletivamente com os sujeitos da Educação do Campo.

A partir da sistematização dos dados emergiram como produto, os quadros 1 e 2, por meio dos quais percebemos o complexo universo em que estão compreendidos os desafios da permanência estudantil na Licenciatura em Educação do Campo - campus Goiabeiras da UFES, cuja teia de fatores articula motivações internas e externas ao curso.

Os resultados sinalizaram que a evasão nesta graduação é um fenômeno multifatorial, assim como ocorre de forma geral no Ensino Superior brasileiro existindo, contudo, motivações que são específicas às necessidades da classe camponesa. Ademais, destacamos o desconhecimento das concepções deste curso como um dos principais desafios, tendo em vista sua influência em quase todas as categorias.

O estudo demonstrou, ainda, que a julgar pelos dados produzidos e pelas tentativas de intervenção frente aos problemas identificados, a universidade ainda não está preparada para receber a classe trabalhadora, em especial a camponesa, que possui tempos, vivências, necessidades e perspectivas diferentes.

Considerando que este é um dos cursos mais novos da UFES, único desta universidade que associa organização curricular em alternância e formação multidisciplinar por área de conhecimento, duas peculiaridades para o Ensino Superior, é compreensível o impacto que esta Licenciatura provoca neste espaço. No entanto, a universidade precisa rever suas práticas e reinventar-se para atender às necessidades da classe popular, que atualmente soma mais da metade dos estudantes das Instituições Federais de Ensino Superior (ANDIFES/FONAPRACE, 2019).

Observamos que há muita luta a ser feita para enfrentar a evasão neste curso, seja no campus universitário, nos espaços públicos, nas escolas e, principalmente, com os próprios sujeitos que participam da construção da Educação do Campo. Espera-se, por fim, que as diretrizes expostas neste artigo possam fomentar possibilidades de intervenção e ações transformadoras da realidade aqui problematizada, de forma conjunta com estudantes, docentes, movimentos sociais do campo e todos aqueles dispostos a lutar por uma educação pública e de qualidade também para os povos camponeses.

Revista Devir Educação, Lavras, vol.5, n2., p.104-125 jul./dez., 2021. 


\section{Referências}

ANDIFES/FONAPRACE. V Pesquisa Nacional de Perfil Socioeconômico e Cultural dos (as) Graduandos (as) das IFES - 2018. Uberlândia, MG: ANDIFES/FONAPRACE, 2019. Disponível em: <http://www.andifes.org.br/wp-content/uploads/2019/05/V-Pesquisa-doPerfil-Socioecono\%CC\%82mico-dos-Estudantes-de-Graduac\%CC\%A7a\%CC\%83o-dasU.pdf>. Acesso em 30 jul. 2019.

BARDIN, Laurence. Análise de Conteúdo. Tradução de Luis Antero Reto e Augusto Pinheiro. Lisboa: Edições 70, 1977.

BRANDÃO, Carlos Rodrigues; BORGES, Maristela Correa. A pesquisa participante: um momento da educação popular. Revista de Educação Popular, Uberlândia, v. 6, p.51-62. jan./dez. 2007. Disponível em:

<http://www.seer.ufu.br/index.php/reveducpop/article/view/19988/10662>. Acesso em: 07 out. 2017.

BRASIL. Ministério de Educação e Cultura. Secretaria da Educação Superior. Diplomação, retenção e evasão nos cursos de graduação em instituições de ensino superior públicas. Brasília: Relatório da Comissão Especial de Estudos sobre Evasão nas Universidades Públicas Brasileiras, ANDIFES/ABRUEM/SESu/MEC, 1996. Disponível em:

$<$ http://www.andifes.org.br/diplomacao-retencao-e-evasao-nos-cursos-de-graduacao-eminstituicoes-de-ensino-superior-publicas/>. Acesso em: 04 out. 2017.

CALDART, Roseli Salete. Por Uma Educação do Campo: traços de uma identidade em construção. In: ARROYO, Miguel Gonzalez; CALDART, Roseli Salete; MOLINA, Mônica Castagna (Org.). Por Uma Educação do Campo. 5.ed. Petrópolis, RJ: Vozes, 2011. p. 147158.

FREIRE, Paulo. A educação na cidade. 5.ed. São Paulo: Cortez, 2001.

FREIRE, Paulo. Pedagogia do oprimido. 64.ed. Rio de Janeiro/São Paulo: Paz e Terra, 2017. GIL, Antonio Carlos. Como elaborar projetos de pesquisa. 4.ed. São Paulo: Atlas, 2002.

GILIOLI, Renato de Sousa Porto. Evasão em instituições federais de ensino superior no Brasil: expansão da rede, Sisu e desafios. Estudo Técnico. Brasília: Câmara dos Deputados, 2016. Disponível em: http://www2.camara.leg.br/a-camara/documentos-e-pesquisa/estudos-enotas-tecnicas/areas-da-conle/tema11/2016_7371_evasao-em-instituicoes-de-ensinosuperior_renato-gilioli. Acesso em: 06 set. 2018.

MOEHLECKE, Sabrina. Avaliação Institucional no ensino superior: como acompanhar a trajetória dos estudantes de graduação? In: V Congresso Luso-Brasileiro de Política e Administração da Educação, 2007, Porto Alegre - RS, Cadernos ANPAE. Porto Alegre: Ed. Anpae, 2007. v. 4. Disponível em:

<http://www.anpae.org.br/congressos_antigos/simposio2007/401.pdf>. Acesso em: 08 abr. 2018.

MOLINA, Mônica Castagna. Expansão das licenciaturas em Educação do Campo: desafios e potencialidades. Educar em Revista, Curitiba-PR, n. 55, p. 145-166, jan./mar. 2015.

Disponível em: 〈http://www.scielo.br/pdf/er/n55/0101-4358-er-55-00145.pdf〉. Acesso em: 08 set. 2018.

MOLINA, Mônica Castagna. Contribuições das Licenciaturas em Educação do Campo para as políticas de formação de educadores. Educação \& Sociedade, Campinas, v. 38, nº 140, 
p.587-609, jul.-set. 2017. Disponível em: <http://www.scielo.br/pdf/es/v38n140/1678-4626es-38-140-00587.pdf >. Acesso em: 30 nov. 2017.

MOVIMENTO DOS TRABALHADORES RURAIS SEM TERRA (MST). Educação Infantil: Movimento da vida, dança do aprender. São Paulo: MST, 2004. - (Caderno de Educação, n. 12).

OLIVEIRA, Rosiska Darcy de; OLIVEIRA, Miguel Darcy de. Pesquisa social e ação educativa: conhecer a realidade para poder transformá-la. IN: BRANDÃO, Carlos Rodrigues (Org.). Pesquisa Participante. 5. ed. São Paulo: Brasiliense, 1985. p. 17-33.

\section{UNIVERSIDADE FEDERAL DO ESPÍRITO SANTO (UFES). Projeto Político Pedagógico} do curso de Licenciatura Plena em Educação do Campo. Vitória, 2014.

VELOSO, Tereza Christina M.A.; ALMEIDA, Edson Pacheco de. Evasão nos cursos de graduação da Universidade Federal de Mato Grosso, campus universitário de Cuiabá: Um processo de exclusão. Revista Série-Estudos, Campo Grande-MS, n ${ }^{\circ}$. 13, p.133-148, jan.jun., 2002. Disponível em: <http://www.serie-estudos.ucdb.br/index.php/serieestudos/article/view/564/453>. Acesso em: 09 abr. 2018.

Recebido em: agosto/2021.

Aprovado em: outubro/2021. 